\title{
Diagnosis of chronic pancreatitis by measurement of lactoferrin in duodenal juice
}

\author{
L MULTIGNER,* C FIGARELLA, AND H SARLES \\ From the Unité de Recherches de Pathologie Digestive, INSERM U 31, Marseille, France, and the \\ Gastroenterology Service of Sainte-Marguerite Hospital, Marseille, France
}

SUMMARY Lactoferrin is a non-enzymatic secretory protein of human pancreas and is specifically increased in pancreatic juice of patients with chronic pancreatitis. Duodenal contents being easier to obtain than pure pancreatic juice, the possibility of using lactoferrin measurement in duodenal juice as a diagnosis test for chronic pancreatitis was explored. Forty-eight patients were studied. Duodenal juice was obtained devoid of salivary contamination by a special double lumen tube. Under these conditions lactoferrin secretion (concentration and output) is increased in patients with chronic pancreatitis. When expressed as the ratio of lactoferrin to lipase units, there was no overlap between chronic pancreatitis and other pancreatic diseases or controls. The simplicity and the reproducibility of the technique on a material as readily available as duodenal juice confirms the diagnostic value of lactoferrin measurement in the assessment of patients with suspected pancreatic disease.

Lactoferrin is an iron-binding protein mainly secreted by mammary glands, and found in various external secretions. ${ }^{1}$ This protein is present in normal pancreatic juice at a very low level but raised levels are found in patients with chronic calcifying pancreatitis. ${ }^{2}$ Lactoferrin is present in pancreatic acinar cells $^{3}$ and its secretion in pancreatic juice is increased after cholecystokinin-pancreozymin (CCK-PZ) stimulation. ${ }^{4}$

A qualitative study on duodenal juice, ${ }^{5}$ and additional studies performed on pure pancreatic juice 6-9 $^{6}$ have shown that lactoferrin is increased in cases of chronic pancreatitis but not in pancreatic carcinoma, acute or acute recurrent pancreatitis, or controls. Moreover, lactoferrin levels in pancreatic juice are related to chronic pancreatitis even in the earlier stage of the disease and the raised levels are not due to increased alcohol intake. ${ }^{9}$

As duodenal juice is obviously easier to collect than pure pancreatic juice, we have studied the possibility of using lactoferrin measurements in duodenal contents after a classical secretin + CCKPZ test. Because of the high levels of lactoferrin in saliva it was necessary to prevent duodenal juice

-Address for reprint requests: Dr C Figarella, Unité de Recherches de Pathologie Digestive, INSERM U 31, 46 Boulevard de la Gaye, 13009 Marseille, France.

Received for publication 25 November 1980 from being contaminated with saliva. In such conditions we demonstrate the great value of lactoferrin determination for diagnosing chronic pancreatitis from other pancreatic diseases and from controls.

\section{Methods}

PATIENTS

Forty-eight patients (43 men and five women) admitted to the Gastroenterology Service of SainteMarguerite Hospital, Marseille, France, for a pancreatic investigation were studied. The patients were divided into the following groups:

\section{Group I}

This group included 22 patients presenting with chronic pancreatitis (20 men and two women, 3373 years old). The aetiology of the disease was as follows: in 20 it was of alcoholic origin (nine calcified and 11 non-calcified), one hereditary form (non-calcified) and one idiopathic form (calcified). Diagnosis was based on a typical clinical history associated with either pancreatic calcifications on plain films of the abdomen or typical biochemical changes (hyperamylasaemia during attacks, decreased glucose tolerance, steatorrhoea). In the noncalcified forms, diagnosis was additionally confirmed by typical modifications of the pancreatic duct after 
endoscopic retrograde cholangio-pancreatography and/or exocrine pancreatic insufficiency after a classical secretin + CCK-PZ test.

\section{Group II}

In this group were eight patients presenting with pancreatic diseases other than chronic pancreatitis (seven men and one woman, 27-62 years old). This group included two patients with carcinoma of the pancreas, three patients with acute pancreatitis (two of alcoholic origin and one after cytomegalovirus infection), and three patients with acute recurrent pancreatitis (two cases due to gallstones and one to a pancreas divisum). These three patients healed after surgery (cholecystectomy, sphincterotomy of the papilla minor), thus proving the acute nature of pancreatic attack.

\section{Group III}

This group consisted of control patients. They were 18 (16 men and two women, 26-58 years old). A pancreatic disease had been ruled out by clinical, radiological, or surgical exploration. Three presented with alcoholic liver cirrhosis, four with duodenal or gastric ulcer, one with diabetes mellitus. For 10 patients it was concluded that an organic disease could be reasonably excluded and that the troubles were either simulated or psychic in origin.

\section{DUODENAL JUICE COLLECTION}

Intubation was carried out early in the morning after a 12 hour fast. Fifteen minutes before the procedure, the patients were sedated with $200 \mathrm{mg}$ phenobarbital and $10 \mathrm{mg}$ metoclopramide. We used a double lumen tube provided with a small inflatable rubber balloon placed between the gastric and duodenal portions as previously described. ${ }^{5}$ This balloon prevents the leakage of gastric juice into the duodenum. The tube was placed under fluoroscopic control with the patient in a prone position, so that its distal end reached the third segment of the duodenum. Then the patient was laid down on his left side: this position was essential to ensure occlusion of the pylorus. Gastric and duodenal aspirations were carried out separately at a constant negative pressure of $20 \mathrm{~cm}$ of water and the contents were collected on crushed ice. At the beginning of the experiment, BSP was injected into the stomach $(4 \mathrm{ml}$ at $5 \mathrm{mg} / \mathrm{ml})$ and any experiment in which the duodenal fluid was found to contain BSP was discarded. BSP was present in the gastric aspirate throughout the experimental time. After one basal 15 minute sample, a single injection of 1 clinical unit/kg body weight secretin and 0.75 Ivy dog units/kg body weight CCK-PZ was given and two 15-minute samples were then collected. Secretin and CCK-PZ were purchased from the Gastrointestinal Research Unit, Karolinska Institutet, Stockholm.

All enzyme and lactoferrin determinations (concentrations and outputs) were performed in the first 15 minute samples after hormonal stimulation. Volume, $\mathrm{pH}$, and colour were recorded.

ENZYME ASSAYS

Lipase activity was determined potentiometrically on a triglyceride emulsion in the presence of biliary salts. ${ }^{10}$ Chymotrypsin was determined using (AcTyr-OEt) as substrate. Phospholipase was assayed on egg-yolk emulsion as previously described.11 Enzymatic units were given by the number of requivalents of substrate hydrolysed per min (International Units: IU).

\section{LACTOFERRIN ASSAY}

To $1 \mathrm{ml}$ duodenal juice, $9 \mathrm{ml}$ cold $\left(-15^{\circ}\right)$ absolute alcohol were added according to Lundh's technique. ${ }^{12}$ The mixture was kept in crushed ice for 30 minutes and then centrifuged in a refrigerated centrifuge for 15 minutes at $7000 \mathrm{rpm}$. The supernatant was eliminated and the precipitate was dissolved with $0.1 \mathrm{ml}$ isotonic saline solution. This solution was used for lactoferrin assay.

Quantitative measurements of lactoferrin were performed by radial immunodiffusion. Immunodiffusion plates (LC-Partigen) and pure standard lactoferrin were prepared in collaboration with $\mathrm{Dr}$ Baudner (Behring Institute, Marburg). Lactoferrin was prepared from a lactoferrin rich fraction isolated from human colostrum and the antiserum was obtained from immunised rabbits. This kit is now available in Europe.

The immunodiffusion plates contained 12 wells. The wells are filled twice with $20 \mu$ l lactoferrin standard or sample to test. Three wells are used for standard lactoferrin $(20 \mu \mathrm{g} / \mathrm{ml}, \quad 10 \mu \mathrm{g} / \mathrm{ml}$, and $5 \mu \mathrm{g} / \mathrm{ml}$, respectively). The nine other wells are used for the duodenal juice. After diffusion for $\mathbf{7 2}$ hours at room temperature, the immunodiffusion plates are washed with isotonic saline solution for three days. Then the plates were coloured during 30 minutes with amidoschwarz or with Coomassie Brilliant Blue. A standard curve was constructed by plotting the square of the diameters of the rings of precipitation against the lactoferrin concentration, and lactoferrin concentrations of samples of duodenal juice were read off from this standard curve. The range of visualisation of lactoferrin is $2-25$ $\mu \mathrm{g} / \mathrm{ml}$. We have observed a within-assay variation of $6 \%$ and between-assay variation of $12 \%$. 
LACTOFERRIN

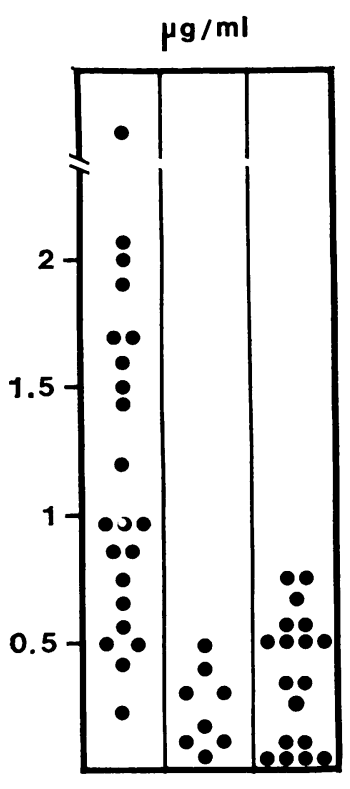

I II III
LIPASE

I.U. $/ \mathrm{ml} \times 10$

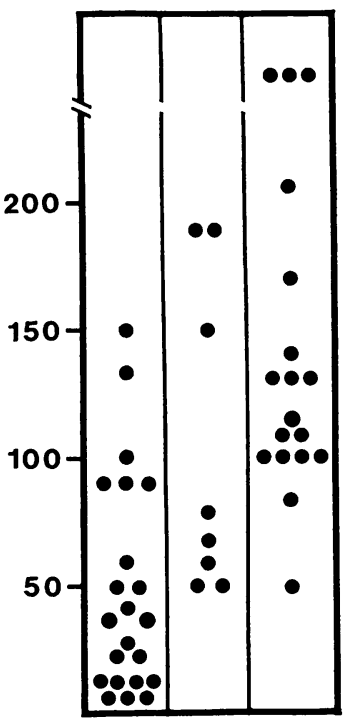

I II III
CHYMOTRYPSIN

I.U. $/ \mathrm{ml}$

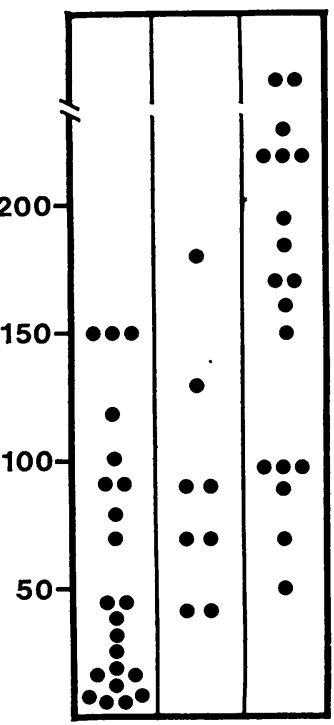

I II III
PHOSPHOLIPASE

I.U./mI

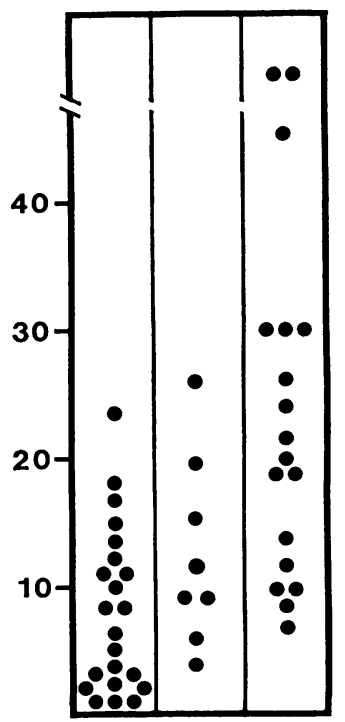

I II III

Fig. 1 Lactoferrin, lipase, chymotrypsin, and phospholipase concentrations in the different groups of patients.

Lactoferrin/enzyme activity ratios were expressed as follows:

$$
\frac{\text { Lactoferrin }(\mu \mathrm{g} / \mathrm{ml})}{\text { Enzyme (units } / \mathrm{ml})} \times 100
$$

\section{Results}

Concentrations and outputs of lactoferrin, lipase, chymotrypsin, and phospholipase are shown in Figs 1 and 2 respectively. As was expected, enzyme concentrations and outputs show a significant decrease in patients presenting with pancreatic diseases (groups I and II), more pronounced in patients with chronic pancreatitis (group I). Conversely, lactoferrin concentrations are significantly higher in chronic pancreatitis compared with the two other patient groups. Moreover, lactoferrin outputs show similar pattern to that of lactoferrin concentrations. As a decreased volume is observed in patients with chronic pancreatitis (data not shown) these results demonstrate unequivocally that the secretion of lactoferrin is increased in these patients in contrast with the secretion of pancreatic enzymes.

We previously reported that the ratio lactoferrin to total protein in pure pancreatic juice is useful to discriminate between chronic pancreatitis and others. ${ }^{9}$ As total protein cannot be accurately determined in duodenal contents, we have expressed our results with the ratio lactoferrin to enzyme activities (Fig. 3). This Figure shows that when the results are expressed in lactoferrin to lipase units ratio, there is no overlap between chronic pancreatitis and other groups of patients. In addition, no significant difference was noticed between calcified and non-calcified chronic pancreatitis.

\section{Discussion}

Previous studies on human pancreatic juice 6-9 have shown that the determination of lactoferrin in pure pancreatic juice may be used as a useful tool for the diagnosis of chronic pancreatitis. Lactoferrin is increased in the juice of patients with chronic pancreatitis but not in the juice of patients with pancreatic cancer. In addition, combined measurements of trypsin and lactoferrin can differenciate between pancreatic cancer and chronic pancreatitis. $^{8}$

However, the collection of pure pancreatic juice is not always simple. Otherwise endoscopic retrograde catheterism of the papilla is usually a secondline test. Our present results show that it is possible 
Diagnosis of chronic pancreatitis by measurement of lactoferrin in duodenal juice
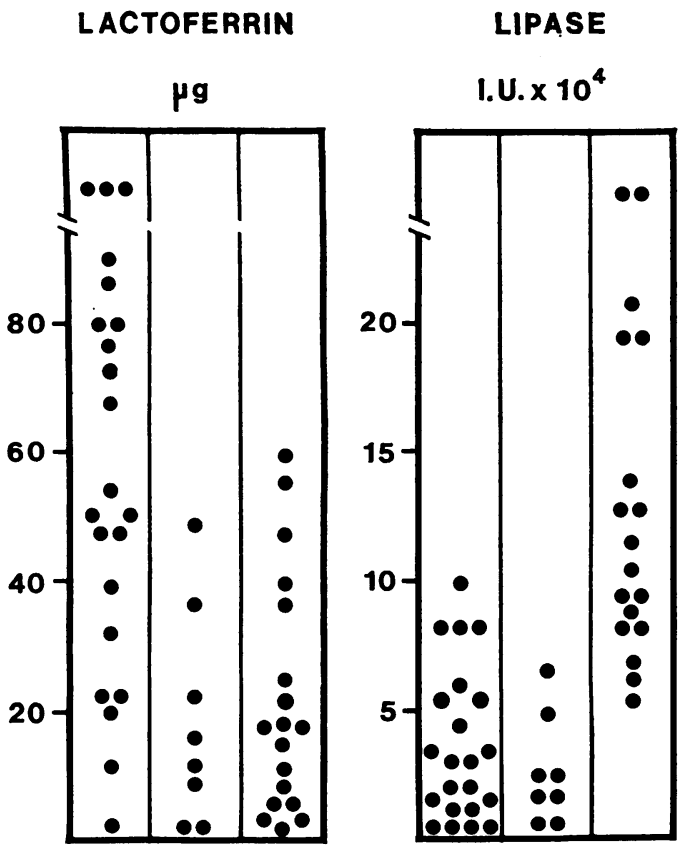

CHYMOTRYPSIN

PHOSPHOLIPASE

I.U. $\times 10^{3}$

I.U. $\times 10^{2}$
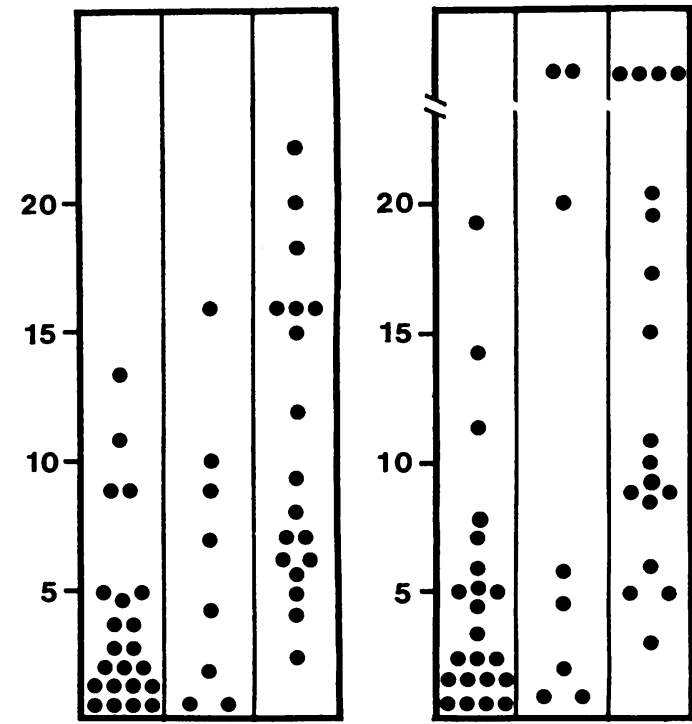

I II III

I II II

I I | I

I II III

Fig. 2 Lactoferrin, lipase, chymotrypsin, and phospholipase outputs in the different groups of patients.

Lf/

LIPASE

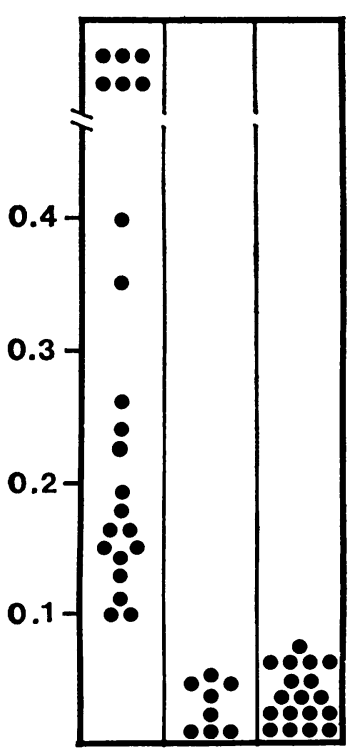

I II III
Lf/

CHYMOTRYPSIN

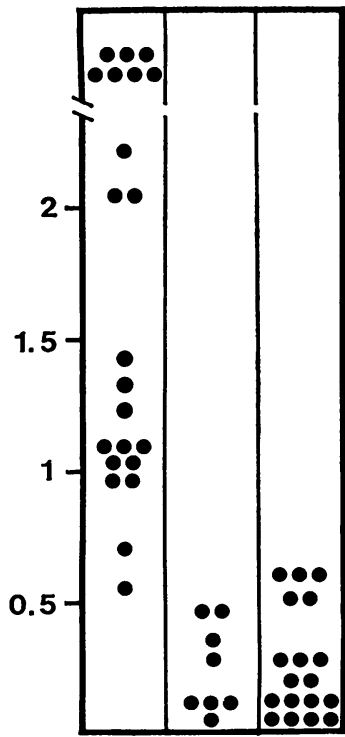

I II III
Lf/

PHOSPHOLIPASE

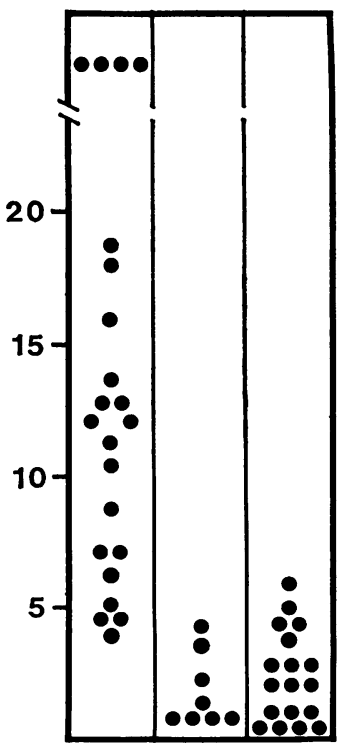

Fig. 3 Lactoferrin ( $L f)$ enzyme activity ratios in the different groups of patients. 
to measure lactoferrin in duodenal juice and that, as found in pure pancreatic juice. lactoferrin is increased in chronic pancreatitis (calcified and noncalcified) compared with other pancreatic diseases and controls. This study confirms that the secretion of lactoferrin is increased in chronic pancreatitis (Fig. 2), as we previously suggested by immunofluorescence studies. ${ }^{3}$ This hypersecretion of lactoferrin is in contrast with the decrease in the secretion of pancreatic enzymes.

Previous qualitative data obtained in duodenal juice of 76 patients with a double diffusion test had shown the same tendency to the increase of lactoferrin in chronic pancreatitis. ${ }^{5}$ However, a positive test was found only in $80 \%$ of patients with chronic pancreatitis; a negative test was found in $100 \%$ of patients with other pancreatic diseases, whereas in controls $10 \%$ gave a positive test and $11.6 \%$ could not be interpreted. These results were probably due to the slight overlap observed between lactoferrin concentrations in the three groups of patients (Fig. 1).

Our present results show clearly that, when expressed as a ratio of lactoferrin to lipase units, no overlap was noticed between chronic pancreatitis and the two other groups of patients. The simplicity and the reproductibility of this technique on a material as readily available as duodenal juice confirm the diagnostic value of lactoferrin measurements to assess a chronic pancreatitis.

\section{References}

${ }^{1}$ Masson P. La lactoferrine. Bruxelles: Arscia Ed.; Paris: Maloine Ed. 1970.
${ }^{2}$ Clemente F, Ribeiro T, Colomb E, Figarella C, Sarles H. Comparaison des protéines de sucs pancréatiques humains normaux et pathologiques. Dosage des protéines sériques et mise en évidence d'une protéine particuliére dans la pancréatite chronique calcifiante. Biochim Biophys Acta 1971; 251 : 456-66.

${ }^{3}$ Colomb E, Pianetta C, Estevenon JP, Guy O, Figarella C, Sarles H. Lactoferrin in human pancreas. Digestion 1976; 14: 242-9.

${ }^{4}$ Fedail SS, Harvey RF, Salmon PR, Read AE. Radioimmunoassay of lactoferrin in pancreatic juice as a test for pancreatic diseases. Lancet 1978; 1: 181-2.

${ }^{5}$ Estevenon JP, Sarles H, Figarella C. Lactoferrin in the duodenal juice of patients with chronic calcifying pancreatitis. Scand J Gastroenterol 1975; 10: 327-30.

${ }^{6}$ Figarella C, Estevenon JP, Sarles H. Measurements of lactoferrin in pancreatic juice. Lancet 1978; 1 : 1105-6.

'Tympner VF, Gutmann W. Lactoferrinkonzentration im veinem Pankressekret bei chronisher Pankreatitis. $Z$ Gastroenterol 1979; 17: 858-61.

${ }^{8}$ Fedail SS, Harvey RF, Salmon PR, Brown P, Read AE. Trypsin and lactoferrin levels in pure pancreatic juice in patients with pancreatic diseases. Gut 1979; 20: 983-6.

${ }^{9}$ Multigner L, Figarella C, Sahel J, Sarles H. Lactoferrin and albumin in human pancreatic juice: a valuable test for diagnosis of pancreatic diseases. Dig Dis Sci 1980; 25: 173-8.

${ }^{10}$ Sarles H, Taulier J, Figarella C. Dosage de la lipase dans le suc duodénal. Rev Franc Etudes Clin Biol 1963; 8: 706-7.

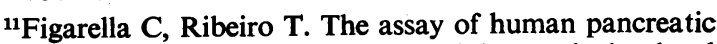
phospholipase $\mathrm{A}$ in pancreatic juice and duodenal contents. Scand J Gastroenterol 1971; 6: 133-7.

${ }^{12}$ Lundh G. Determination of trypsin and chymotrypsin in human intestinal content. Scand J Clin Lab Invest 1957; 9: 229-32. 